\title{
Relationship Between Disease Severity and Balance Function in Patients with Myasthenia Gravis
}

\author{
Adesti Permanasari ${ }^{\mathrm{a}}$, Indrayuni Lukitra Wardhani ${ }^{\mathrm{b} *}$, Yudith Dian Prawitric ${ }^{\mathrm{c}}$ \\ ${ }^{\text {a,b,c }}$ Department of Physical Medicine and Rehabilitation, Faculty of Medicine Airlangga University 60132, Dr. Soetomo General \\ Hospital, Surabaya, Indonesia \\ *Corresponding Author: indrayuni-1-w@fk.unair.ac.id
}

\begin{abstract}
Background: Myasthenia Gravis (MG) is an autoimmune disease that affects neuromuscular transmission with various clinical manifestations, including muscle weakness and fatigue. Muscle weakness worsens the severity of MG patients and impairs functional ability. Muscle weakness in MG patients that is accompanied by repetitive physical activity causes loss of muscle endurance and affects balance function and movement.

Aim: To determine the relationship between disease severity and balance function in patients with Myasthenia Gravis.

Methods: This research is a cross sectional study. The Myasthenia Gravis Composite (MGC) scale was used to assess the disease severity of Myasthenia Gravis. One leg stance (OLS) test was used to assess static balance function and the Time Up and Go (TUG) test was used to assess dynamic balance function and functional ability. Rank-Spearman test was used to assess the correlation between disease severity and balance function in patients with Myasthenia Gravis.

Results: Thirty-one patients with Myasthenia Gravis were included by consecutive sampling. A significant correlation between disease severity and dynamic balance function was found $(p=0.002 ; \rho=0.531)$ with CI 95\%.

Conclusion: There is a relationship between disease severity and dynamic balance function in patients with Myasthenia Gravis.
\end{abstract}

Keywords: Severity, balance, Myasthenia Gravis, MGC scale, one leg stance, TUG test

\section{Introduction}

Myasthenia Gravis (MG) is an autoimmune disease that affects neuromuscular transmission with various clinical manifestations, including muscle weakness and fatigue (Sieb, 2014). Muscle weakness worsens the severity of MG patients and impairs functional ability. Muscle weakness in MG patients that is accompanied by repetitive physical activity causes loss of muscle endurance and affects balance function and movement (Chang et al., 2021; Lee et al., 2020).

The severity scale for Myasthenia Gravis was developed to evaluate the patient's clinical condition and response to treatment or exercise. Since 2012, the MGFA has recommended the MGC scale (Myasthenia Gravis Composite) as a daily clinical evaluation tool for patients with Myasthenia Gravis. It is an assessment that combines the objective evaluation of the examiner and the subjective report of the patient. The MGC scale provides a better rating for all degrees of severity than the other scales because of the weight of the validated assessment items (Burns et al., 2010; Muppidi, 2017). 
Based on the findings from previous studies above, this study aimed to determine the relationship between disease severity and balance function in patients with MG and to determine the associated factors that contribute.

\section{Method and Materials}

This research is an analytic observational study with a cross-sectional design. Subjects were recruited consecutively from the Neurology Outpatient Clinic of Dr. Soetomo Hospital Surabaya, from April to June 2021. The inclusion criteria are age 18-60 years, confirmed with MG by neurologist, cooperative, agreeing to participate, and willing to sign a consent. The exclusion criteria are patient with severe symptoms (MGFA class IIIB), patient with myasthenia crisis, pregnancy, obesity, history of musculoskeletal disease, history of other neurological disease, visual impairment, vestibular disorders, and suffering from infectious diseases.

Eligible participants underwent examinations and functional tests to determine their demographic profile, disease severity, and balance function. Disease severity was assessed using the Myasthenia Gravis Composite (MGC) Scale, which was developed by Burns et al. by selecting items from Quantitative Myasthenia Gravis (QMG), Manual Muscle Test (MMT), and Myasthenia Gravis-Activities of Daily Living (MG-ADL) and by considering quality of life, disease severity risk, prognosis, validity, and reliability (Burns et al., 2008). The items in the MGC were assessed using 4 levels of severity (normal/no symptoms to severe), with the total score ranging from 0 (no symptoms) to 50 (very severe) (Burns et al., 2008).

One-leg stance (OLS) test was used to assess static balance while Time Up and Go (TUG) test was used to assess dynamic balance and functional ability. The Time Up and Go (TUG) test is a test of basic mobility skills, with the score given based on the time completion in seconds (Podsiadlo and Richardson, 1991).

The data was analyzed using the SPSS 26.0 version. Demographic information was presented as a mean, standard deviation, and percentage. The Rank-Spearman test was used to assess between disease severity and balance function. The influence of body mass index (BMI), the patient's current age, and the time of last MG medication consumption on the balance function of patients with Myasthenia Gravis was analyzed using multivariate regression analysis, with a P-value $<0.05$ considered significant. This study was approved by the ethical committee of Dr. Soetomo General Hospital, Surabaya, Indonesia.

\section{Results}

\subsection{Characteristics of the research subjects}

The total eligible subjects in this study were 31 patients ( 9 males and 22 females). The majority of the subjects $(71 \%)$ were women, with a mean age of $45.23( \pm 9.79)$ years and an onset age of $39.61( \pm 20.27)$ years. All subjects have generalized MG type, with more than half of the subjects having normal BMI $(51.6 \%)$ and none of them having a history of smoking or falling. Most subjects last took MG medication 2-4 hours before the interview and examination $(80.6 \%)$. 
Table 1. Demographic profile

\begin{tabular}{|c|c|c|}
\hline Variable & n (31) & $(\%)$ \\
\hline \multicolumn{3}{|l|}{ Sex } \\
\hline Male & 9 & 29 \\
\hline Female & 22 & 71 \\
\hline \multicolumn{3}{|l|}{ Type of MG } \\
\hline Generalized & 31 & 100 \\
\hline Ocular & 0 & 0 \\
\hline \multicolumn{3}{|l|}{ BMI } \\
\hline Underweight & 2 & 6,5 \\
\hline Normal & 16 & 51,6 \\
\hline Overweight & 2 & 6,5 \\
\hline Pre-Obese & 4 & 12,9 \\
\hline Obese Grade 1 & 7 & 22,6 \\
\hline \multicolumn{3}{|l|}{ Alcohol Use } \\
\hline No & 10 & 32.3 \\
\hline Yes & 20 & 64.5 \\
\hline \multicolumn{3}{|l|}{ Cigarette Smoking } \\
\hline No & 31 & 100 \\
\hline Yes & 0 & 0 \\
\hline \multicolumn{3}{|l|}{ History of Fall } \\
\hline No & 31 & 100 \\
\hline Yes & 0 & 0 \\
\hline \multicolumn{3}{|c|}{ Time of the last MG medication consumption } \\
\hline$<2$ hours & 1 & 3,2 \\
\hline 2-4 hours & 25 & 80,6 \\
\hline$>4$ hours & 5 & 16,1 \\
\hline
\end{tabular}

Abbreviations: $\mathrm{BMI}=$ Body Mass Index

Table 2. Subject characteristic

\begin{tabular}{lll}
\hline \multicolumn{1}{c}{ Variable } & Mean & ;D \\
\hline Age (year) & 45.23 & 9.79 \\
Age at onset (year) & 39.61 & 10.27 \\
MGC & 5.06 & 6.07 \\
Duration of medication (years) & 5.45 & 5.18 \\
Mestinon dose (tablet 60 mg)/day & 3.87 & 1.28 \\
Methylprednisolone dose (tablet 4 mg)/day & 0.39 & 1.02 \\
Imuran dose (tablet 50 mg)/day & 0.03 & 0.18 \\
OLS OE (seconds) & 23,52 & 15,95 \\
OLS CE (seconds) & 8,20 & 9,51 \\
TUG (seconds) & 11,14 & 2,95 \\
\hline
\end{tabular}

Abbreviations: MGC = Myasthenia Gravis Composite Scale; OLS OE = one leg stance with open eyes; OLS CE = one leg stance with closed eyes; TUG = Time Up and Go test 


\subsection{Correlation between the disease severity and balance function}

Normality test using Shapiro-Wilk and the obtained data were not normally distributed for the disease severity and the result of one leg stance and time up and go test. Rank-Spearman correlation test was used to analyze the correlation between the disease severity and balance function, and we got a significant correlation ( $p=0.002 ; \rho=0.531$, CI 95\%) between disease severity and dynamic balance that is measured by TUG, but there was no correlation between disease severity and static balance which is measured by OLS.

Table 3. Rank Spearman Correlation Test

\begin{tabular}{lll}
\hline & \multicolumn{1}{c}{ Spearman's rho } & MG-ADL \\
\hline \multirow{3}{*}{ OLS OE (seconds) } & Correlation Coefficient & $-0,124$ \\
& Sig. (2-tailed) & 0,508 \\
& $\mathrm{~N}$ & 31 \\
\hline \multirow{2}{*}{ OLS CE (seconds) } & Correlation Coefficient & $-0,030$ \\
& Sig. (2-tailed) & 0,872 \\
& $\mathrm{~N}$ & 31 \\
\multirow{2}{*}{ TUG (seconds) } & Correlation Coefficient & 0,531 \\
& Sig. (2-tailed) & $0,002^{*}$ \\
\hline Abbreviations: MGC: & $\mathrm{N}$ & 31 \\
\hline
\end{tabular}

Eyes; TUG: Time Up and Go test

* Significant: $\mathrm{p}<0.05$

\subsection{Factors affecting balance function in patients with Myasthenia Gravis}

Table 4-6 shows the multivariate regression predictive analysis which analyzed the influence of body mass index (BMI), the patient's current age, and the time of last MG medication on the balance function of patients with Myasthenia Gravis. We found that BMI, the patient's current age, and the time of last MG medication consumption didn't influence the patient's balance function simultaneously, both static $(p=0,265 ; p=0,346)$ and dynamic $(\mathrm{p}=0,268)$.

Table 4. Multivariate regression predictive analysis for One Leg Stance test with open eyes

\begin{tabular}{llllll}
\hline Model & Sum of Squares & df & Mean Square & F & P-Value \\
\hline Regression & 1024,608 & 3 & 341,536 & 1,397 & 0,265 \\
Residual & 6603,140 & 27 & 244,561 & & \\
Total & 7627,748 & 30 & & & \\
\hline
\end{tabular}

Table 5. Multivariate regression predictive analysis for One Leg Stance test with closed eyes

\begin{tabular}{llllll}
\hline Model & Sum of Squares & df & Mean Square & F & P-Value \\
\hline Regression & 307,989 & 3 & 102,663 & 1,153 & 0,346 \\
Residual & 2403,141 & 27 & 89,005 & & \\
Total & 2711,130 & 30 & & & \\
\hline
\end{tabular}


Table 6. Multivariate regression predictive analysis for Time Up and Go test

\begin{tabular}{llllll}
\hline Model & Sum of Squares & df & Mean Square & F & P-Value \\
\hline Regression & 34,953 & 3 & 11,651 & 1,388 & 0,268 \\
Residual & 226,642 & 27 & 8,394 & & \\
Total & 261,595 & 30 & & & \\
\hline
\end{tabular}

\section{Discussion}

\subsection{Characteristics of research subjects}

Most of the subjects included in this study were women, with a mean age of 45 years old, and all of the subjects had generalized MG type. A comparison of early and late onset MG in previous studies showed that MG predominates in young adult women and older men (Fan et al., 2019; Melzer et al., 2016). This is supported by a cohort study which showed cases of MG in women were higher in the first 5 decades of age, while MG in men occurred more in the 6th decade of age (Alshekhlee et al., 2009). Berrih-Aknin and Fan et al. explained that the early symptoms of MG usually manifest as an ocular type with characteristic weakness of the extraocular muscles and ocular misalignment. Nearly $90 \%$ of patients with ocular MG will develop into general MG within 3 years of onset (Berrih-Aknin and Le Panse, 2014; Fan et al., 2019).

In this study, of 31 subjects with myasthenia gravis, none had a history of falls. This is in accordance with several previous studies which explained that there were no reports of repeated falls or falls in young Myasthenia Gravis patients, but there were reports of repeated falls in older MG patients (McHugh et al., 2019; Aragonès et al., 2014; Chua et al., 2000).

In comparison to the population (Springer et al., 2007) the average participant in this study has a poor static balance function and a good dynamic balance function. Abnormal balance function is a parameter for an increased risk of falling and can be associated with the presence of peripheral neuropathy and intermittent claudication (Cuğ et al., 2014).

The time of the last MG drug consumption in this study was 2-4 hours before the interview or examination. This is in accordance with several previous studies which stated that the administration of exercise or function testing in Myasthenia Gravis patients was carried out within 2 hours after taking pyridostigmine (O'Connor et al., 2020; Westerberg et al., 2017). This is due to the structure of pyridostigmine which is absorbed slowly and in small amounts by the gastrointestinal tract, while most of the proportion is excreted by the kidneys. The effect of an oral dose of pyridostigmine starts approximately 30 minutes after intake, with improvement in muscle function in patients with myasthenia gravis lasting 3-4 hours, and can be maintained with repeated doses (Anderson and Pope, 2017).

\subsection{Correlation between the disease severity and balance function}

Significant correlation was found between disease severity of Myasthenia Gravis and dynamic balance function. This is in accordance with the study conducted by Wong et al. in 2014 and Westerberg et al. in 2017 which showed an increase in dynamic balance and functional mobility in Myasthenia Gravis patients who were given balance exercise therapy, and was associated with a reduction in disease severity (Wong et al., 2014; Westerberg et al., 2017).

\subsection{Factors affecting balance function in patients with Myasthenia Gravis}

In this study, body mass index, patient's current age, and time of last MG medication did not influence the balance function of Myasthenia Gravis patients simultaneously. The subject's age in this study were ranging from 20-60 years old, with mean age of 45.23 years old, and most had normal BMI (51.6\%). These results are in accordance with previous studies (Wada et al., 2008; Yoshida-Intern, 2007; Barnedh et al., 2006) which mentioned that the elderly have a higher risk factor for the occurrence of falls due to complications of various 
comorbidities associated with the metabolic syndrome, including hypertension and obesity, thus affecting skeletal muscle mass and strength as well as balance function. Lee et al. also explained that obesity is strongly correlated with decreased postural stability in the adult population aged 24-61 years (Lee et al., 2020). However, the results of the balance test in this study showed a decrease in balance function which may be associated with decreased postural stability. Decreased postural stability can be caused by a decrease in the individual's capacity to use postural control strategies, including endurance and lower extremity muscle strength which can be assessed through isokinetic examination, and respiratory muscle endurance and strength as predictors of exercise function capacity which can be assessed using lung function capacity tests, such as a spirometer or a six-minute walking test (6MWT) function test (Lee et al., 2020; Chang et al., 2021; Laessoe et al., 2019).

The absence of effect of time of last medication consumption on the balance function in this study may be related to the optimal time to muscle function improvement in Myasthenia Gravis (Anderson and Pope, 2017). Further examination and research is needed regarding endurance and muscle strength of the lower extremities through isokinetic examination and examination of respiratory muscle endurance and strength in Myasthenia Gravis patients to assess the patient's lung function capacity that can influence balance function of patient with Myasthenia Gravis.

\section{Conclusion}

Disease severity in patients with Myasthenia gravis correlates with dynamic balance function. Therefore, assessment of severity can be used as a parameter to detect the balance function of a patient with Myasthenia Gravis. However, body mass index, patient's current age, and time of last medication consumption did not seem to influence the balance function of a patient with Myasthenia Gravis. Further research is needed to determine the associated factors.

\section{References}

Alshekhlee, A.M.D.M., Miles, J.D., Katirji, B., Preston, D.C. and Kaminski, H.J., 2009. Incidence and mortality rates of myasthenia gravis and myasthenic crisis in US hospitals. Neurology, 72(18), pp.1548-1554.

Anderson, T. and Pope, C.N., 2017. Pyridostigmine.

Aragonès, J.M., Roura-Poch, P., Hernández-Ocampo, E.M., Alonso, F., Pont-Lluelles, M., Xandri, I., Bolíbar, I. and Illa, I., 2014. Myasthenia gravis: a disease of the very old. Journal of the American Geriatrics Society, 62(1), pp.196-197

Barnedh, H., Sitorus, F. and Ali, W., 2006. Penilaian keseimbangan menggunakan skala keseimbangan berg pada lansia di kelompok lansia puskesmas tebet. UNIVERSITAS INDONESIA.

Berrih-Aknin, S. and Le Panse, R., 2014. Myasthenia gravis: a comprehensive review of immune dysregulation and etiological mechanisms. Journal of autoimmunity, 52, pp.90-100.

Burns, T.M., Conaway, M.R., Cutter, G.R. and Sanders, D.B., 2008. Construction of an efficient evaluative instrument for myasthenia gravis: the MG composite. Muscle \& Nerve: Official Journal of the American Association of Electrodiagnostic Medicine, 38(6), pp.1553-1562.

Burns, T.M., Conaway, M. and Sanders, D.B., 2010. The MG Composite: A valid and reliable outcome measure for myasthenia gravis. Neurology, 74(18), pp.1434-1440.

Chang, C.C., Chen, Y.K., Chiu, H.C. and Yeh, J.H., 2021. Changes in Physical Fitness and Body Composition Associated with Physical Exercise in Patients with Myasthenia Gravis: A Longitudinal Prospective Study. Journal of Clinical Medicine, 10(17), p.4031. 
Chua, E., McLoughlin, C.A.R.I.N.A. and Sharma, A.K., 2000. Myasthenia gravis and recurrent falls in an elderly patient. Age and ageing, 29(1), pp.83-84.

Cuğ, M., Özdemir, R.A. and Ak, E., 2014. Influence of Leg Dominance on Single-Leg Stance Performance During Dynamic Conditions: An Investigation into the Validity of Symmetry Hypothesis for Dynamic Postural Control in Healthy Individuals. Turkish Journal of Physical Medicine \& Rehabilitation/Turkiye Fiziksel Tip ve Rehabilitasyon Dergisi, 60(1).

Fan, L., Ma, S., Yang, Y., Yan, Z., Li, J. and Li, Z., 2019. Clinical differences of early and late-onset myasthenia gravis in 985 patients. Neurological research, 41(1), pp.45-51.

Laessoe, U., Larsen, C.B., Schunck, L.N., Lehmann, L.J. and Iversen, H., 2019. Age related differences in balance approached by a novel dual-task test of anticipatory postural control strategies. Plos one, 14(6), p.e0218371.

Lee, J.J., Hong, D.W., Lee, S.A., Soh, Y., Yang, M., Choi, K.M., Won, C.W. and Chon, J., 2020. Relationship between obesity and balance in the community-dwelling elderly population: A cross-sectional analysis. American journal of physical medicine \& rehabilitation, 99(1), pp.65-70.

McHugh, D., Isakov, A., Reddy, R., Xian, S., Napier, F. and Ocava, L., 2019. Myasthenia Gravis Presenting as Recurrent Falls in a Young Man (P1. 9-055).

Melzer, N., Ruck, T., Fuhr, P., Gold, R., Hohlfeld, R., Marx, A., Melms, A., Tackenberg, B., Schalke, B., Schneider-Gold, C. and Zimprich, F., 2016. Clinical features, pathogenesis, and treatment of myasthenia gravis: a supplement to the Guidelines of the German Neurological Society. Journal of neurology, 263(8), pp.1473-1494.

Muppidi, S., 2017. Outcome measures in myasthenia gravis: incorporation into clinical practice. Journal of clinical neuromuscular disease, 18(3), pp.135-146.

O'Connor, L., Westerberg, E. and Punga, A.R., 2020. Myasthenia gravis and physical exercise: a novel paradigm. Frontiers in Neurology, 11

Podsiadlo, D. and Richardson, S., 1991. The timed "Up \& Go": a test of basic functional mobility for frail elderly persons. Journal of the American geriatrics Society, 39(2), pp.142-148.

Sadri, Y., Haghi-Ashtiani, B., Zamani, B. and Akhundi, F.H., 2015. Study of demographic, clinical, laboratory and electromyographic symptoms in Myasthenia Gravis patients referred to the neurology clinic of Rasoul Akram hospital in 2015. Journal of medicine and life, 8(Spec Iss 3), p.218.

Sieb, J.P., 2014. Myasthenia gravis: an update for the clinician. Clinical \& Experimental Immunology, 175(3), pp.408-418.

Springer, B.A., Marin, R., Cyhan, T., Roberts, H. and Gill, N.W., 2007. Normative values for the unipedal stance test with eyes open and closed. Journal of geriatric physical therapy, 30(1), pp.8-15.

Wada, M., Naganuma, H., Tokumasu, K., Hashimoto, S.I., Ito, A. and Okamoto, M., 2008. Arteriosclerotic changes as background factors in patients with peripheral vestibular disorders. Int Tinnitus J, 14(2), pp.131-134.

Westerberg, E., Molin, C.J., Lindblad, I., Emtner, M. and Punga, A.R., 2017. Physical exercise in myasthenia gravis is safe and improves neuromuscular parameters and physical performance-based measures: A pilot study. Muscle \& nerve, 56(2), pp.207-214.

Wong, T.Y., Ferreira, A., Hughes, R., Carter, G. and Mitchell, P., 2014. Epidemiology and disease burden of pathologic myopia and myopic choroidal neovascularization: an evidence-based systematic review. American journal of ophthalmology, 157(1), pp.9-25.

Yoshida-Intern, S., 2007. A global report on falls prevention epidemiology of falls. Geneva: WHO. 